\title{
EMPLOYEE ENGAGEMENT: THE EFFECTS OF WORK-HOME/HOME- WORK INTERACTION AND PSYCHOLOGICAL CONDITIONS
}

\author{
Sebastiaan Rothmann \\ North-West University, Vanderbijlpark \\ Candice Baumann \\ University of Namibia, Windhoek \\ Accepted: May 2014
}

\begin{abstract}
The aim of this study was to investigate the relationships between work-home/home-work interaction, psychological conditions and employee engagement. A cross-sectional survey was used. The participants were 292 employees of a uranium mine in Namibia residing in towns distant from their workplace. The following measuring instruments were used: Survey Work-Home Interaction - Nijmegen, Psychological Conditions Scale and Work Engagement Scale. Positive work-home interaction and negative home-work interaction had direct positive and negative effects on psychological meaningfulness and psychological availability respectively. Psychological meaningfulness, psychological availability, positive work-home interaction and positive home-work interaction had direct effects on employee engagement. An analysis of the indirect effects showed that positive work-home interaction affected employee engagement via experiences of psychological meaningfulness and psychological availability. Negative home-work interaction affected employee engagement negatively via low psychological meaningfulness and low psychological availability. Implementing policies to promote meaningfulness and availability at work, to build positive workhome interaction and to protect employees against negative home-work interference, will contribute to personal engagement at work.
\end{abstract}

Key words: work-home interaction, home-work interaction, psychological meaningfulness, psychological availability, employee engagement

JEL: J240

1

\section{Introduction}

Engaging employees is an important strategy for organisations, for various reasons: Engagement may contribute to the psychological wellbeing of individuals at work (Rothmann, 2013). Furthermore, engaged employees are less inclined to be absent from work (Harter, Schmidt, Killham \& Asplund, 2006), present a better service to the clients, and contribute to organisations' productivity and profitability (Harter, Schmidt \& Hayes, 2002). Various definitions of employee engagement are found in the literature. Maslach, Schaufeli and Leiter (2001) define employee engagement in terms of energy and involvement, while Schaufeli and Bakker (2004) regard vigour, absorption and dedication as central concepts in their definition of work engagement. Kahn and Heaphy (2014) define personal engagement as bringing in one's self to one's work-role performance. Whilst employee engagement research seems to be flourishing in the United States and Europe, Rothmann (2014) stresses the importance of conducting such research in other countries.

Personal engagement is defined by Simpson (2008) as physically, cognitively, and emotionally employing or articulating oneself during work role performances. When engaged, an employee is understood to be physically involved, cognitively alert, and emotionally attached (Kahn, 1990; Kahn \& Heaphy, 2014; May, Gilson \& Harter, 2004). The physical component of engagement refers to having high levels of energy and mental flexibility while working, being willing to put extra effort 
into one's work, and persisting in the face of difficulties. The emotional component entails a strong involvement with one's work and also when one experiences a sense of worth, interest, self-importance, and challenge. The cognitive component refers to being completely focused and contently immersed in one's work, but experiencing difficulty to disconnect from the work as time draws nearer to leave one's work until the next day.

In his model of engagement as an extension of the self, Kahn (1990) identified three psychological conditions (i.e. psychological meaningfulness, psychological availability and psychological safety) that shape personal engagement through contexts at work (Kahn \& Heaphy, 2014; May et al., 2004). Psychological meaningfulness is defined as the feeling that one is receiving a return on investment of one's self in a currency of physical, cognitive, or emotional energy, while psychological availability refers to the readiness and confidence of an individual to engage in his/her work role (Kahn, 1990; May et al., 2004). Activities outside the workplace could draw away individuals' energies from their work and make them less psychologically available for their work roles. These activities - and the time demands associated with them are likely to distract an individual's attention so that he/she is unable to focus on his/her role tasks. Psychological safety refers to the experience of being able to act in a way that is natural, and to be able to use and employ all skills and knowledge in a role without having to fear ridicule or negative consequences (Kahn, 1990). Little information is available on the effects of positive work-home and home-work interaction on employee engagement via psychological conditions.

The understanding of the effects of workhome and home-work interaction on employee well-being has grown (Geurts, Taris, Kompier, Dikkers, Van Hoof \& Kinnunen, 2005). However, most studies focused on married working mothers who had to balance work and family (e.g. childcare) responsibilities (Munn, 2013). Although family responsibilities are often regarded by employees as one of the top demands leading to work stress (Bakker, Ten Brummelhuis, Prins \& Van der Heijden, 2011), work can also energise people and contribute to experiences of psychological meaningfulness, competence and availability to work, and personal engagement. Previous research showed that work-home and home-work interaction affect the engagement of employees (Bakker et al., 2011; Lingard, Brown, Bradley, Bailey \& Townsend, 2007; Mostert, Cronjé \& Pienaar, 2006; Mostert, Peeters \& Rost, 2011). Two psychological conditions, namely psychological meaningfulness and psychological availability, seem relevant for transferring the effects of work-home/home-work interaction to employee engagement (Kahn, 1990; Kahn \& Heapy, 2014; May et al., 2004). However, no studies focused on the psychological conditions which mediate between work-home/home-work interaction and employee engagement.

The organisation in this study, which is located in the Namib Desert in Namibia, started operations in 1976 and is the fifthlargest uranium mine in the world, with 8 per cent of the global output. The mine is located close to Arandis, a small town which is mostly occupied by mine workers. A total of 76 per cent of the employees live in two other towns, Swakopmund and Walvis Bay, which are respectively 70 and 100 kilometres from the mine. These towns have relatively good infrastructure (e.g. schools, housing, and shopping centres), while Arandis lacks the infrastructure to accommodate employees. In addition, transport facilities to the mine are limited to buses and own vehicles. People living in the two towns and working at the mine spend between two and three hours per day travelling to and from their work. Due to the distance from home to work and the required work schedule, there is clearly interaction in terms of personal hours lost due to travel time to and from the job. A large percentage of the employees have to leave their homes early in the morning and arrive home late in the afternoon. Parents might experience practical problems regarding care of their children during working days. For instance, mothers who work at the mine cannot leave their jobs to attend to the needs of their children. Another form of interaction is that some employees and their families live close to their work (in Arandis) in a small community which is relatively isolated from non-mining 
communities. On the positive side, the mine creates jobs and provides various benefits associated with corporate employers (e.g. competitive salaries, training and development opportunities, and good working conditions). These factors make it interesting to study both positive and negative interactions from work to home and from home to work.

No relevant literature regarding work-home and home-work interaction, psychological conditions and employee engagement was found pertaining to the mining sector specifically in the context of a developing country in Africa. People often seek employment at mines as they know that salaries, fringe benefits, human resource management and the nature of the work are attractive. But these are not the only factors that would keep them engaged. Work-home and home-work interaction might affect employees' engagement (May et al., 2004). Furthermore, employees want more from their jobs than salary and fringe benefits; they want to feel competent and experience their work as meaningful (Munn, 2013). In addition, both positive and negative work-home and home-work interaction might affect employee engagement specifically via experiences of psychological meaningfulness and psychological availability. Therefore the research question for this study is as follows: Do work-home and home-work interaction affect employee engagement at a uranium mine and can specific psychological conditions (that precede engagement) explain such effects? The information gathered in this study is required to plan interventions to manage the work/life integration and engagement of employees.

\section{2}

\section{Literature review}

\subsection{Psychological conditions and employee engagement}

According to Lewis (2011), employee engagement is a state that resides within the person rather than the job. Understanding of the contribution of psychological conditions to personal engagement is important because employee engagement varies among individuals in the same job and from task to task.
The experienced psychological conditions of meaningfulness, availability and safety lie at the heart of many engagement models (Crawford, Rich, Buckman \& Bergeron, 2014). Research regarding the mediating effects of psychological conditions between work-home/ home-work interactions and employee engagement is necessary to understand how engagement can be managed and increased (Olivier \& Rothmann, 2007).

At work, psychological meaningfulness refers to the value of a work goal or purpose, judged in relation to an individual's own ideals or standards (Renn \& Vandenberg, 1995; Rothmann \& Welsh, 2013) and the coherence that he/she experiences (Ryff, 1989). Experiences at work contribute to psychological meaningfulness, not only because people spend a large part of their lives at work (Holbeche \& Springett, 2004), but also because people expect more from their jobs than just a salary and benefits. Studies showed that psychological meaningfulness predicts large percentages of the variance in employee engagement (May et al., 2004; Rothmann \& Rothmann, 2010; Rothmann \& Welsh, 2013). Factors which are associated with psychological meaningfulness at work include using one's strengths, work role fit, a values-based culture, caring about employees, social support, opportunities to learn, the organisation's mission and employee socialisation (May et al., 2004; Munn, 2013).

Psychological availability (also referred to as competence by Spreitzer, 1995) refers to the ability to engage as a result of having the necessary cognitive, emotional and physical resources (May et al., 2004). Individuals who are psychologically available feel capable and prepared to invest their resources into role performances at work, while individuals who are not available lack resources or feel distracted from investing them into role performances (Crawford et al., 2014). As members of social systems, employees experience distractions (e.g. from non-work demands) to the point that they have less energy to invest in role performances. Employees feel less psychologically available when activities outside the workplace draw their energies away, resulting in disengagement from their roles. Based on social exchange theory, employees feel obliged to 
engage as repayment for the resources they receive from their organisation (Saks, 2006). Individuals protect themselves from exposure to emotional, cognitive and physical demands when they feel overwhelmed (Kahn \& Heapy, 2014). They become distant towards their roles and other people, which imply that the authentic selves become unavailable for performance in a specific role.

\subsection{Work-home and home-work interaction}

Work-family conflict has been defined as a form of inter-role disagreement in which the work and family domains are incompatible, resulting in role strain (Greenhaus \& Beutell, 1985). There are three forms of work-family conflict, namely time-based conflict, strainbased conflict, and behaviour-based conflict (Geurts \& Demerouti, 2003). Time-based conflict refers to the demands from one domain, which are associated with the accomplishment of one role, that make it physically impossible to meet demands from the other domain - or being preoccupied with one role while attempting to fulfil the demands of another role (Bartolome \& Evans, 1979). Strain-based conflict refers to strain (e.g. tension, anxiety, fatigue, depression, irritability) caused by the contribution in one domain (role) that makes it complicated to meet the terms of the other domain (another role). Behaviour-based conflict refers to particular forms of role behaviour that are in contrast with the prospects of behaviour in another role.

Geurts et al. (2005) distinguish between two concepts - role scarcity and role enhancement - which can be studied to unravel work-home and home-work interaction. Role scarcity refers to work-home interaction as a type of inter-role conflict in which role pressures from the work and family domains are mutually incompatible (Geurts et al., 2005). It is difficult to juggle multiple roles (partner, father and employee) with limited time and energy. Role enhancement implies that fulfilling multiple roles may produce resources (e.g. energy mobilisation, skill acquisition, greater self-esteem) that facilitate functioning in both life spheres (Geurts et al., 2005). This means that balancing one's home and work domains in an effective manner could save an individual a lot of energy, and could help one to acquire optimal skills in both domains and to feel more in charge of the situation. In short, work-life balance is seeking to obtain an optimal balance between one's work and one's life in general (Bratton \& Gold, 2003).

Geurts et al. (2005) found a fourdimensional structure of work-home/homework interactions, consisting of positive workhome interaction (e.g. a good/fair working environment), negative work-home interaction (e.g. a poor salary and work overload), positive home-work interaction (e.g. emotional support from family), and negative home-work interaction (e.g. no support from family). This means that if a person loves his/her job and there is no support from his/her family, it may cause a negative home-work spillover, but if the family supports him/her, it could result in a positive home-work spillover. The same is true for work-home spillover. A negative workhome spillover could be caused by an unfavourable working environment and a positive work-home spillover could be due to good and fair relations at work. Contrary to the role strain hypothesis, it is possible that developing one's skills at work to optimally utilise one's energies might enhance one's productivity in the non-work domain. This process is referred to as positive spillover or role enhancement (Grzywacz \& Marks, 2000). In maintaining a work-life balance, there may be some positive outcomes in terms of work circumstances that may benefit non-work circumstances, and the other way around.

Concerning positive work-home spillover, Crouter (1984) found that training in decisionmaking skills at work resulted in individuals employing the newly acquired tactics at home to deal with their children more efficiently. Studies also showed that when individuals get support from their spouses and have the platform at home to discuss work issues, they tend to manage the pressures at work better (Gattiker \& Larwood, 1990). Employed married mothers generally enjoy a greater sense of happiness and better physical health than unemployed married mothers or employed single mothers without children (Geurts \& Demerouti, 2003). The study by Grzywacz and Marks (2000) showed that both resources at work (e.g. decision latitude, support from co- 
workers and supervisors) and at home (e.g. support from a spouse) were associated with lower levels of negative spillover and higher levels of positive spillover between work and family. Barriers at work (e.g. a demanding job) and at home (e.g. disagreement with one's spouse) were associated with higher levels of negative spillover and lower levels of positive spillover between work and family (Geurts \& Demerouti, 2003).

Spillover is one of the six recurring linking mechanisms between work and non-work roles depicted by Edwards and Rothbard (2000) in the work-life literature. Two other important mechanisms are compensation and segmentation (Demerouti \& Geurts, 2004). Compensation refers to a non-work and work relationship where individuals over-involve themselves in one role to make up for deficiencies in another role; this in turn allows for a negative relationship between constructs in the two roles. An example or evidence of compensation is shown in a study done by Rothbard (2001) which showed that women who experienced negative affect from family were more engaged at work. Segmentation differs from spillover and compensation in that it suggests no logical relationship between work and non-work roles. The segmentation model describes the non-association of the two roles in that work and family do not influence one another (Edwards \& Rothbard, 2000). According to Eckenrode and Gore (1990), segmentation is an active psychological process, which means that when it comes to work and family, people may choose to maintain a boundary between the two roles. Park, Fritz and Jex (2011) found that employees with a preference for segmenting the work from the home domain experienced greater psychological detachment from work during nonwork time.

\section{The mediating effects of psychological conditions}

The various types of inter-role conflict (timebased, strain-based and behaviour-based) and role enhancement could affect employee engagement indirectly via experiences of psychological meaningfulness and psychological availability.

Research on positive psychological functioning (Keyes, 2007; Ryff, 1989) has shown that basic psychological needs associated with living a meaningful life must be satisfied if optimal functioning of individuals is to be achieved. Matuska and Christiansen (2008) also linked meaningful lifestyles to psychological meaningfulness. Munn (2013) suggests that positive and negative work-home and home-work interaction affect employees' experiences of psychological meaningfulness of work. Delle Fave, Brdar, Freire, VellaBrodrick and Wissing (2011) found that family life has a strong effect on experiences of psychological meaningfulness. Interaction between individuals' work and home roles affects their sense of a balanced life (Sirgy \& $\mathrm{Wu}, 2009$ ), which impacts their experiences of psychological meaningfulness at work. According to Munn (2013), positive work-home/ home-work interaction contributes moderately to psychological meaningfulness.

Work is an important context to engage individuals in goal-directed activities, and to provide meaning (Cameron, Dutton \& Quinn, 2003). Therefore psychological meaningfulness is expected to be related to engagement (Fairlie, 2011). Furthermore, various studies confirmed that negative work-home and homework interaction is negatively related to employee engagement, while positive workhome and home-work interaction is positively related to employee engagement (Marais, Mostert, Geurts \& Taris, 2009; Mostert et al., 2006). Research has shown that individuals are willing to engage in their work when they experience psychological meaningfulness (Kahn, 1990; May et al., 2004; Rothmann \& Welsh, 2013). Employees who experience negative work-home/home-work interactions could therefore experience less meaningfulness in their work, which could result in reduced engagement at work. Conversely, employees who experience positive work-home/homework interactions could experience more meaningfulness in their work, which could result in increased engagement. Therefore psychological meaningfulness may mediate the relationships between work-home/home-work interaction and employee engagement.

Psychological availability (i.e. feeling competent as a result of having the necessary cognitive, emotional and physical resources) could mediate the relationship between work- 
home and home-work interactions and employee engagement (Kahn \& Heaphy, 2014). When work-life conflict occurs, it means that there is more than one role that needs satisfying and that there is some form of imbalance between the roles. In both work and family there needs to be some measure of consistency between the roles with regard to the input of psychological availability for a proper balance to be achieved between the two roles. This can be related to Marks and MacDermid's (1996) finding that role balance will only occur when all the roles in the role system of an individual have been equally satisfied. According to Hall and Richter (1989), individuals' energies at work may be strained by outside activities, which will in turn make them less psychologically available in their work roles. Conversely, psychological availability and employee engagement can be influenced positively by family engagement (Rothbard, 2001).

\section{3}

\section{Aim and hypotheses}

The aim of this study was to investigate the relationship between work-home and homework interaction, psychological conditions and employee engagement.

The following hypotheses are set based on the discussion above:

Hypothesis 1: Negative work-home and home-work interactions are inversely related to psychological availability.

Hypothesis 2: Positive work-home and home-work interactions are positively related to psychological availability.

Hypothesis 3: Negative work-home and home-work interactions are inversely related to psychological meaningfulness.

Hypothesis 4: Positive work-home and home-work interactions are positively related to psychological meaningfulness.

Hypothesis 5: Psychological meaningfulness is positively related to employee engagement.

Hypothesis 6: Psychological availability is positively related to employee engagement.

Hypothesis 7: Work-home and home-work interaction indirectly affect employee engagement via psychological meaningfulness.

Hypothesis 8: Work-home and home-work interaction indirectly affect employee engagement via psychological availability.

\section{4}

\section{Method}

\subsection{Research design}

A cross-sectional survey design was utilised in this study (Huysamen, 2004). Within the crosssectional design, latent variable modelling was used to investigate the fit of the hypothesised models as well as indirect effects (Muthen \& Muthen, 2012).

\subsection{Participants}

The participants were employees of a uranium mine who are residents of Swakopmund, Walvis Bay and Arandis. The total population of the study at the end of April 2010 comprised 1468 employees. The sample was stratified based on rank and gender. A stratified random sample was taken $(N=300)$. All females in some ranks were targeted to ensure sufficient sizes of sub-samples. A total of 291 individuals completed the questionnaires. With regard to the respondents' fluency in English, a grade 12 certificate had to be presented. Table 1 illustrates the characteristics of the sample.

Table 1

Characteristics of participants

\begin{tabular}{|l|l|l|l|}
\hline Items & Category & Frequency & $\%$ \\
\hline Gender & Male & 220 & 75.3 \\
& Female & 72 & 24.7 \\
\hline \multirow{2}{*}{ Work level } & Subordinate & 249 & 85.3 \\
& Supervisor & 32 & 11.0 \\
& Manager & 11 & 3.8 \\
\hline Parental status & Yes & 214 & 73.3 \\
& No & 78 & 26.7 \\
\hline Marital status & Married & 212 & 72.6 \\
& Single & 80 & 27.4 \\
\hline
\end{tabular}




\subsection{Measuring instruments}

The Survey Work-Home Interaction Nijmegen (SWING; Geurts et al., 2005) was used to measure the work-home interaction experienced by participants. The SWING is a 30-item work-home interaction measure which assesses four types of interactions, namely (1) negative work-home interaction (NWHI), which refers to the negative impact of the work situation on one's functioning at home (eight items; e.g. 'How often does it happen that you are irritable at home because your work is demanding?'); (2) negative home-work interaction (NHWI), which refers to the negative impact of the home situation on one's job performance (five items; e.g. 'How often does it happen that the situation at home makes you so irritable that you take your frustrations out on your colleagues?'); (3) positive work-home interaction (PWHI), which refers to the positive influence of the work situation on one's functioning at home (five items; e.g. 'How often does it happen that you come home cheerfully after a successful day at work, positively affecting the atmosphere at home?'); and (4) positive home-work interaction (PHWI), which refers to the positive impact of one's home situation on one's job performance (five items; e.g. 'How often does it happen that you manage your time at work more efficiently because at home you have to do that as well?'). All items are scored on a four-point frequency rating scale, ranging from 0 (never) to 3 (always). Baumann (2011) showed evidence for the construct validity of the SWING in a sample of mine employees in Namibia. Geurts et al. (2005) report Cronbach alpha coefficients of 0.84 for NWHI and 0.75 for PWHI, as well as 0.75 for NHWI and 0.81 for PHWI. In a South African police sample, Marais et al. (2009) provided evidence of the construct validity, construct equivalence and reliability of the scales. They reported the following Cronbach alpha coefficients for the SWING: $\mathrm{NWHI}=0.90, \mathrm{PWHI}=0.84$, NHWI $=0.87$, and $\mathrm{PHWI}=0.82$.

The Psychological Conditions Scale (PCS; May et al., 2004) was used to measure psychological availability and psychological meaningfulness. For all the items, an agreement/disagreement Likert format ranging from 1 (never) to 5 (always) was used. An item that measures psychological availability is ' $I$ am confident in my ability to deal with problems that come up at work'. An item on the questionnaire that measures psychological meaningfulness is 'My job activities are personally meaningful to me'. Psychological availability is measured by six items $(\alpha=0.90)$ drawn from the research of May et al. (2004). These items measure the degree of availability (cognitive, emotional and physical) that individuals discovered in their work-related activities. Psychological meaningfulness is measured by six items $(\alpha=0.90)$ drawn from the research of Spreitzer (1995) and May et al. (2004). These items measure the degree of meaning that individuals discovered in their work-related activities. Baumann (2011) showed evidence for the construct validity of the PCS in a sample of mine employees in Namibia.

The Work Engagement Scale (WES; May et al., 2004, as adapted by Diedericks \& Rothmann, 2013) was used to measure employee engagement. For all items, a Likert scale ranging from 1 (never) to 5 (always) was used. The items reflect each of the three components of Kahn's (1990) conceptualisation of employee engagement, namely cognitive ( 2 items; e.g. 'I am very absorbed in my work'), emotional (3 items; e.g. 'I am passionate about my job') and physical engagement ( 3 items, e.g. 'I am full of energy in my work'). In their research, Olivier and Rothmann (2007) found evidence for a onefactor engagement model consisting of cognitive, emotional and physical engagement ( $\alpha=0.72$ ), which is consistent with the findings of May et al. (2004).

\subsection{Procedure}

The researcher engaged the support of three human resource practitioners from different sections of the mine's Human Resources Department to assist with the administration of questionnaires. The researcher followed up with the selected employees to personally explain the purpose of the research and to request voluntary participation in the research. The objective of the study was explained to the human resource practitioners so that they could have more insight when giving the information to the potential participants, to ensure that they 
would be able to make informed decisions about their involvement in the study. The instruments used simple questions in English which study participants with a basic literacy rate should be able to understand. After obtaining informed consent, the human resource practitioners distributed the questionnaires, allowed time for the questionnaires to be returned, and finally returned the completed questionnaires to the researcher.

\subsection{Statistical analysis}

The analysis of the data was carried out by means of Mplus version 7.11 (Muthén \& Muthén, 1998-2012). Items of the three questionnaires were defined as categorical and the weighted least squares with corrections to means and variances (WLSMV) were used as estimator. The following indices produced by Mplus were used in this study: a) absolute fit indices, including the chi-square statistic which is the test of absolute fit of the model, and the Root Mean Square Error of Approximation (RMSEA), and b) incremental fit indices, including the Tucker-Lewis Index (TLI) and the Comparative Fit Index (CFI) (Kline, 2010). TLI and CFI values higher than 0.90 are considered acceptable. RMSEA values lower than 0.08 indicate a close fit between the model and the data. Composite reliabilities $(\rho)$ of scales were computed by means of a formula based on the sum of squares of standardised loadings and the sum of standardised variance of error terms (Raykov, 2009; Wang \& Wang, 2012).

\section{5}

\section{Results}

First, the results of tests of competing measurement models are reported. Second, the results of tests of alternative structural models are reported.

\subsection{Testing the measurement model}

Using confirmatory factor analysis (CFA), an eight-factor measurement model as well as alternative models were tested to assess whether items would load significantly onto the scales with which they were associated. Four measurement models were tested. Model 1 consisted of seven latent variables, namely a) NWHI (measured by 10 observed variables); b) PWHI (measured by five observed variables); c) NHWI (measured by 10 observed variables); d) PHWI (measured by five observed variables); e) psychological meaningfulness (measured by six observed variables); f) psychological availability (measured by eight observed variables), and g) employee engagement (measured by eight observed variables). All the latent variables in model 1 were allowed to correlate.

Models 2, 3, and 4 followed the same template: model 2 was specified with 14 observed variables measuring psychological conditions (without the two first-order latent variables, namely psychological meaningfulness and psychological availability); model 3 was specified with 20 observed variables measuring NWHI and NHWI (without the two first-order latent variables, namely NWHI and NHWI) and 10 observed variables measuring PWHI and PHWI (without the two first-order latent variables, namely PWHI and PHWI); model 4 was specified with all items loading on a single factor (measured by 52 observed variables).

Two fit statistics, namely the Akaike Information Criterion (AIC; a comparative measure of fit, is meaningful when different models are estimated) and Bayes Information Criterion (BIC; an index of model parsimony) were used to compare alternative measurement models (Kline, 2010). Table 2 presents the fit statistics of the various models.

Table 2

Fit statistics for the competing measurement models

\begin{tabular}{|l|c|c|c|c|c|c|c|}
\hline Model & $\chi^{2}$ & df & CFI & TLI & RMSEA & AIC & BIC \\
\hline Model 1 & $1787.96^{*}$ & 1253 & 0.96 & 0.96 & 0.04 & 28445.94 & 29515.88 \\
\hline Model 2 & $2048.02^{*}$ & 1259 & 0.94 & 0.94 & 0.05 & 28667.53 & 29715.40 \\
\hline Model 3 & $2347.35^{\star}$ & 1264 & 0.92 & 0.92 & 0.05 & 28947.42 & 29976.91 \\
\hline Model 4 & 6317.80 & 1274 & 0.12 & 0.63 & 0.62 & 31302.07 & 32294.79 \\
\hline
\end{tabular}


Comparison of the AIC and BIC values indicates that model 1 fitted the data best. The $\chi^{2}(1253, n=292)=1787.96$ of the hypothesised model was statistically significant $(p<0.001)$, but the other fit indices indicated good fit of the model to the data: CFI $=0.96$, TLI $=0.96$, RMSEA $=0.04$. Standardised coefficients from items to factors ranged from 0.61 to 0.91 . The results also indicated that the relationship between each observed variable and its respective construct was statistically significant $(p<0.01)$.

\subsection{Testing the structural model}

Reliabilities and correlations among workhome/home-work interaction, psychological meaningfulness, psychological availability and employee engagement are reported in Table 3.

Table 3

Reliabilities and correlations of the scales

\begin{tabular}{|l|l|c|c|c|c|c|c|c|}
\hline \multicolumn{2}{|c}{ Variable } & $\boldsymbol{\rho}$ & $\mathbf{1}$ & $\mathbf{2}$ & $\mathbf{3}$ & $\mathbf{4}$ & $\mathbf{5}$ & $\mathbf{6}$ \\
\hline 1 & $\mathrm{NWHI}$ & 0.93 & - & - & - & - & - & - \\
\hline 2 & $\mathrm{PWHI}$ & 0.89 & $-0.16^{* *}$ & - & - & - & - & - \\
\hline 3 & $\mathrm{NHWI}$ & 0.90 & $0.21^{* *}$ & -0.04 & - & - & - & \\
\hline 4 & $\mathrm{PHWI}$ & 0.92 & $0.24^{* *}$ & $0.50^{* *}$ & -0.07 & - & - & - \\
\hline 5 & Meaningfulness & 0.92 & $-0.18^{* *}$ & $0.14^{* *}$ & $-0.12^{* *}$ & $0.10^{* *}$ & - & - \\
\hline 6 & Availability & 0.92 & $-0.11^{* *}$ & $0.14^{* *}$ & $-0.16^{* *}$ & $0.14^{* *}$ & $0.40^{* *}$ & - \\
\hline 7 & Employee engagement & 0.93 & $-0.16^{* *}$ & $0.24^{* *}$ & $-0.14^{* *}$ & $0.23^{* *}$ & $0.42^{* *}$ & $0.43^{* *}$ \\
\hline
\end{tabular}

$N W H I=$ negative work-home interaction; $P W H I=$ positive work-home interaction; $N H W I=$ negative home-work interaction; $P H W I=$ positive home-work interaction ${ }^{* *} p<0.01$

Table 3 shows that the reliabilities of the constructs were acceptable, compared to the guideline of 0.70 (Wang \& Wang, 2012). Statistically significant $(p<0.01)$ relationships exist between all the variables, except NHWI and PWHI, as well as NHWI and PHWI.

The measurement model formed the basis of the structural model. The hypothesised relationships shown in the model were tested, using latent variable modelling as implemented by Mplus (Muthén \& Muthén, 1998-2012). An acceptable fit of the model to the data was found: $\chi^{2}=1787.96, d f=1253$, TLI $=0.96$, CFI $=0.96$, and RMSEA $=0.04$. Table 4 shows the standardised regression coefficients estimated by Mplus for the structural model.

\section{Hypotheses 1 and 2}

For the portion of the model predicting psychological availability, Table 4 indicates that the path coefficient of PWHI $(\beta=0.20, p$ $<0.01)$ was statistically significant and had the expected sign. Psychological availability had a positive relation with positive work-home interaction. Furthermore, the path coefficient of NHWI $(\beta=-0.34, p<0.01)$ was statistically significant and had the expected sign. Psychological availability had a negative relation with negative home-work interaction. The WLSMV- estimated equation accounted for a moderate proportion of the variance in psychological availability $\left(R^{2}=0.17\right)$. Hypotheses 1 and 2 are partially supported.

\section{Hypothesis 3 and 4}

For the portion of the model predicting psychological meaningfulness, Table 4 indicates that the path coefficient of PWHI $(\beta=0.18, p<0.01)$ was statistically significant and had the expected sign. Psychological meaningfulness had a positive relation with positive work-home interaction. Furthermore, the path coefficient of NHWI $(\beta=-0.19, p<0.01)$ was statistically significant and had the expected sign. Psychological meaningfulness had a negative relation with negative home-work interaction. The WLSMV-estimated equation accounted for a moderate proportion of the variance in psychological meaningfulness $\left(R^{2}=0.14\right)$. Hypotheses 3 and 4 are partially supported.

\section{Hypothesis 5 and 6}

For the portion of the model predicting employee engagement, Table 4 reveals that the path coefficients of PWHI $(\beta=0.17, p>0.01)$, PHWI $(\beta=0.17, p>0.01)$, psychological meaningfulness $(\beta=0.35, p>0.25)$ and psychological availability $(\beta=0.17, p>0.01)$ 
were statistically significant and had the expected signs. The WLSMV-estimated equation accounted for a large proportion of the variance in employee engagement $\left(R^{2}=\right.$
0.46). Hypothesis 5 and 6 are supported: Employee engagement was positively related to psychological meaningfulness and psychological availability.

Table 4

Standardised regression coefficients of the variables

\begin{tabular}{|c|c|c|c|c|}
\hline Variables & Estimate & SE & Est/SE & $p$ \\
\hline \multicolumn{5}{|c|}{ Engagement on } \\
\hline NWHI & 0.01 & 0.06 & 0.22 & 0.829 \\
\hline PWHI & 0.17 & 0.06 & 2.89 & $0.004^{* *}$ \\
\hline NHWI & -0.06 & 0.06 & -0.90 & 0.368 \\
\hline PHWI & 0.15 & 0.05 & 2.84 & $0.005^{\star *}$ \\
\hline Meaningfulness & 0.35 & 0.05 & 7.07 & $0.000^{* *}$ \\
\hline Availability & 0.25 & 0.06 & 4.38 & $0.000^{* *}$ \\
\hline \multicolumn{5}{|c|}{ Meaning on } \\
\hline NWHI & -0.13 & 0.07 & -1.88 & 0.060 \\
\hline PWHI & 0.18 & 0.07 & 2.49 & $0.013^{* *}$ \\
\hline NHWI & -0.19 & 0.07 & -2.79 & $0.005^{\star *}$ \\
\hline PHWI & 0.03 & 0.07 & 0.37 & 0.709 \\
\hline \multicolumn{5}{|c|}{ Availability on } \\
\hline NWHI & 0.08 & 0.07 & 1.10 & 0.270 \\
\hline PWHI & 0.20 & 0.08 & 2.62 & $0.009^{\star *}$ \\
\hline NHWI & -0.34 & 0.06 & -5.76 & $0.000^{* *}$ \\
\hline PHWI & 0.08 & 0.08 & 1.12 & 0.264 \\
\hline
\end{tabular}

$N W H I=$ negative work-home interaction; $P W H I=$ positive work-home interaction; $N H W I=$ negative home-work interaction; $P H W I=$ positive home-work interaction

${ }^{* *} p<0.01$

Figure 1

WLSMV estimates for the hypothesised model of employee engagement (standardised solution)

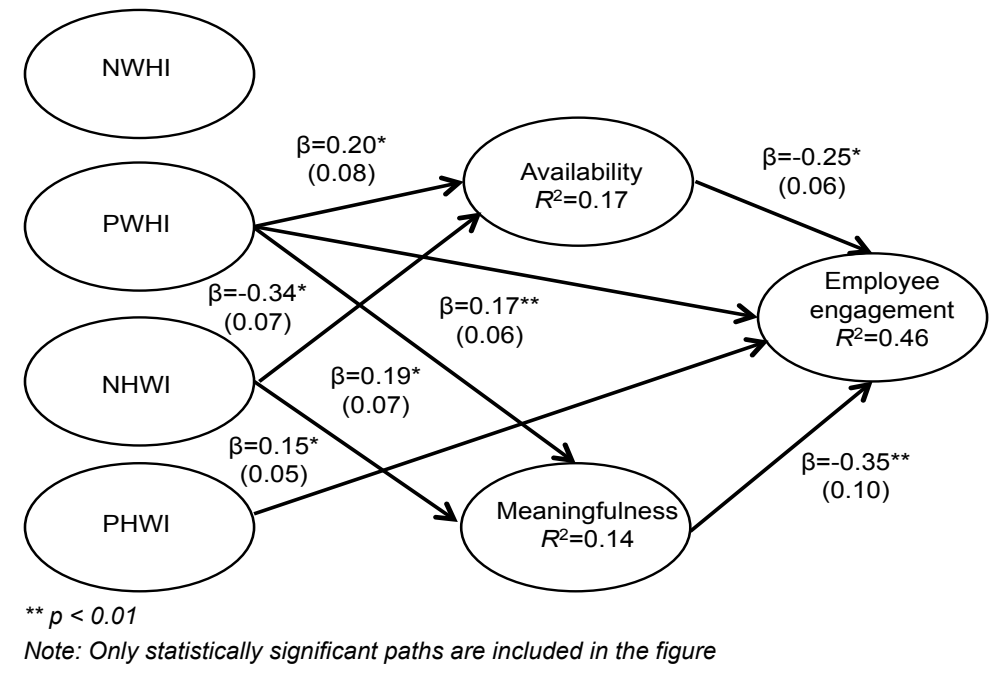

Given the cross-sectional nature of the data, two other competing models were also tested: Model 1.2 included paths from psychological

meaningfulness and availability to employee engagement and from NWHI, PWHI, NHWI and PHWI to psychological availability, but 
the paths from NWHI, PWHI, NHWI and PHWI to psychological meaningfulness were constrained to zero. Model 1.3 included paths from psychological meaningfulness and availability to employee engagement and from NWHI, PWHI, NHWI and PHWI to psychological meaningfulness, but the paths from NWHI, PWHI, NHWI and PHWI to psychological availability were constrained to zero.

Model 1.2 showed the following fit statistics: $\chi^{2}(1257, N=292)=2084.54 ; p<$ $0.001 ; \mathrm{CFI}=0.94, \mathrm{TLI}=0.94$ and $\mathrm{RMSEA}=$ 0.04 (90\% CI 0.04-0.05). Model 1.3 showed the following fit statistics: $\chi^{2}(1257, N=292)=$ 2084.54; $p<0.001 ; \mathrm{CFI}=0.94, \mathrm{TLI}=0.94$ and RMSEA $=0.05$ (90\% CI 0.04-0.05). The following changes in chi-square $\left(\Delta \chi^{2}\right)$ were found: Models 1.1 and $1.2\left(\Delta \chi^{2}=74.93, \Delta d f=\right.$ $4, p<0.0001)$, and models 1.1 and $1.3\left(\Delta \chi^{2}=\right.$ 72.96, $\Delta d f=4, p<0.0001)$.

\subsection{Indirect effects}

To determine whether any relationships in the model were indirectly affected by workhome/home-work interaction, the procedure explained by Hayes (2009) was used. Bootstrapping was used to construct two-sided bias-corrected 95 per cent confidence intervals (CIs) so as to evaluate indirect effects. Lower and upper CIs are reported (see Table 5).

Table 5

Indirect effects of work-home/home-work interaction

\begin{tabular}{|c|c|c|c|c|}
\hline \multirow{2}{*}{ Variable } & \multirow{2}{*}{ Estimate } & \multirow{2}{*}{ SE } & \multicolumn{2}{|c|}{$95 \% \mathrm{BC} \mathrm{Cl}$} \\
\hline & & & Lower & Upper \\
\hline \multicolumn{5}{|c|}{ Psychological meaningfulness } \\
\hline NWHI & -0.05 & 0.03 & -0.11 & 0.02 \\
\hline PWHI & 0.06 & 0.03 & 0.01 & 0.12 \\
\hline NHWI & -0.06 & 0.03 & -0.13 & 0.01 \\
\hline PHWI & 0.01 & 0.03 & -0.04 & 0.06 \\
\hline \multicolumn{5}{|c|}{ Psychological availability } \\
\hline NWHI & 0.02 & 0.02 & -0.02 & 0.06 \\
\hline PWHI & 0.05 & 0.02 & 0.01 & 0.09 \\
\hline NHWI & -0.09 & 0.04 & -0.16 & -0.02 \\
\hline PHWI & 0.02 & 0.02 & -0.02 & 0.06 \\
\hline
\end{tabular}

Note: $S E$ = standard error; 95 per cent $B C \mathrm{Cl}=95$ per cent bias-corrected confidence intervals $N W H I=$ negative work-home interaction; $P W H I=$ positive work-home interaction; $N H W I=$ negative home-work interaction; $\mathrm{PHWI}=$ positive home-work interaction $p<0.01$

Regarding the indirect effects of PHWI on employee engagement, the 95 per cent CIs for psychological meaningfulness did not include zero. Hypothesis 6 is partially supported: positive work-home interaction impacts employee engagement via psychological meaningfulness. Regarding the indirect effects of PWHI and NHWI on employee engagement, the 95 per cent CIs for psychological availability did not include zeros. Therefore positive work-home interaction and negative home-work interaction indirectly affect employee engagement via psychological availability. Hypotheses 7 and 8 are partially supported.

Taken together, the results suggest that the relationships posited in the model account for a substantial amount of the covariation in the data. The model accounts for 46 per cent of the variance in employee engagement, 14 per cent of the variance in psychological meaningfulness and 17 per cent of the variance in psychological availability, lending more empirical support for the model's fit.

\section{6}

\section{Discussion}

The aim of this study was to investigate the relationships between work-home and homework interaction, psychological conditions and employee engagement. The results showed that psychological meaningfulness and availability as well as work-life balance accounted for a large proportion of the variance in employee 
engagement. Positive work-home interaction was positively associated with experiences of psychological meaningfulness and availability at work, while negative home-work interaction impacted psychological availability negatively. An analysis of the indirect effects showed that psychological meaningfulness partially mediated the relationship between positive work-home interaction and employee engagement. Psychological availability mediated the relationship between positive work-home interaction as well as negative home-work interaction and employee engagement.

Negative home-work interaction was negatively associated with psychological availability, while positive work-home interaction was positively associated with psychological availability. Psychological availability indicates whether employees feel ready or confident to engage in their work roles, given that they are also engaged in other life activities (Kahn, 1990; May et al., 2004). Low psychological availability associated with a lack of positive work-home interaction and negative homework interaction were associated with an inability to personally engage at work, presumably because employees lack cognitive, emotional and physical resources and they feel distracted from investing into role performances (Crawford et al., 2014; May et al., 2004; Spreitzer, 1995). Employees feel less psychologically available when activities outside the workplace draw their energies away. They become distant towards their roles and other people, which imply that their authentic selves become unavailable for performance in a specific role. Given the physical distance between the employees' work and homes, it is understandable that psychological availability is negatively associated with negative home-work interaction. When children are small, ill or experience difficulties, a guardian is not in town, and support is not available, then employees will not feel ready or confident to engage in their work.

Positive work-home interaction impacted psychological meaningfulness positively, while negative home-work interaction impacted meaningfulness negatively. Given that family life has an effect on psychological meaningfulness (Delle Fave et al., 2011; Munn, 2013) it is understandable that low negative home- work interference contribute to employees' experiences of meaningfulness at work. Furthermore, based on the role enhancement principle, positive work-home interaction resulting from support and learning in the workplace seems to contribute to psychological meaningfulness. Employees who experience psychological meaningfulness feel that they are receiving a return on investment of themselves in a currency of physical, cognitive, or emotional energy (Kahn, 1990; Kahn \& Heapy, 2014). Interaction between individuals' work and home roles affects their sense of a balanced life (Sirgy \& Wu, 2009), which impacts their experiences of psychological meaningfulness at work.

Concerning work-home/home-work interaction, the results showed that positive workhome interaction (e.g. a good/fair working environment) and a negative home-work interaction (no support from family) play an important role in affecting the dependent variables in the structural model of employee engagement. Positive work-home spillover does not only affect psychological availability and psychological meaningfulness, but also employee engagement (Geurts et al., 2005; Grzywacz \& Marks, 2000). Moreover, negative home-work spillover also affects experiences of psychological availability, psychological meaningfulness and engagement of employees. Because of distances between work and home, the lack of (family) support plays an important role in affecting employees' feelings of competence, their experiences of psychological meaningfulness and their engagement at work. If employees are not affected by negative home-work interaction and they experience positive work-home interaction, they tend to be more engaged in their work (Marais et al., 2009; Mostert et al., 2006).

The results regarding negative interactions from home to work may be related to the depletion argument (Edwards \& Rothbard, 2000; Rothbard, 2001) and the resource drain perspective (Greenhaus \& Beutell, 1985). Depletion is based on the notion that an individual has only a certain fixed amount of physiological and psychological resources to spend or utilise and that he/she makes exchanges or substitutions in order to accommodate those fixed resources (Rothbard, 
2001). The results are also closely linked to the strain-based conflict perspective, which argues that strain in one role affects performance in another role (Edwards \& Rothbard, 2000; Greenhaus \& Beutell, 1985).

Regarding positive experiences, the results showed that positive work-home interaction impacted employee engagement directly as well as indirectly (via psychological meaningfulness and psychological availability). Specific positive experiences that happen at work, spill over to the home domain, and promote both meaningfulness and employee engagement. Interestingly, positive home-work interaction did not have any direct effects on psychological meaningfulness and psychological availability. However, positive home-work interaction did affect employee engagement significantly. These results are related to the enrichment process by Rothbard (2001) on the concepts of role accumulation and multiple roles. The enrichment process suggests that engagement in one role may be related to another role. This is seen in the results of this study whereby positive spillover from one domain results in a positive outcome in the other domain. The enrichment argument implies that more role commitments can be beneficial to an individual, rather than putting strain on or draining him/her (Rothbard, 2001).

This study showed that psychological meaningfulness and availability are important psychological conditions to consider in promoting the engagement of employees (Matuska \& Christiansen, 2008). The results also confirm that psychological conditions make an important contribution to explaining the effects of positive work-home and negative home-work interaction on employee engagement. Low negative home-work interaction and high positive work-home interaction contribute to employees feeling available and competent to engage in their work. Also, low negative workhome interference and high positive workhome interaction contribute to the experience of psychological meaningfulness at work, which in turn impacts employee engagement positively. Psychological meaningfulness, psychological availability, and work-home/homework interaction explained a large percentage of variance in personal engagement at work.
This study had various limitations. The study did not include the entire mining sector of Namibia, but focused on a particular mining company. Furthermore, a cross-sectional survey was used in this study; therefore, causality of relationships could not be proven. In this regard Halbesleben, Harvey and Bolino (2009) argued for a reversed causal ordering between engagement and work-life interference, i.e. that employees might create the interference with their family roles because they are too engaged in their work. Longitudinal studies are necessary to assess the indirect effects of work-home and homework interactions on employee engagement.

\section{7}

\section{Recommendations}

Managers and employees should become aware of the concepts of engagement and work-life balance, and the relation of the concepts. Implementation of programmes directed at the attainment of a work-life balance will prove vital to the organisations and their bottom line. Such training and development programmes are necessary to ensure that employees remain healthy and competent as well as engaged. The implementation of a performance management system based on task agreements between managers and employees should be investigated. If used properly, a performance management system could provide information regarding work-home/home-work interaction and engagement.

Future research needs to explore the worklife balance and employee engagement between the different gender roles, cultures, and hierarchies within a company. The relationship between work-life balance and employee engagement should be investigated in a wider variety of organisations, using larger samples. The results of this study suggest that further research is warranted at both the individual and the organisational level to better understand the pathways to work-life balance and employee engagement. Research is also necessary to identify other variables which affect psychological meaningfulness and availability. 


\section{References}

BAKKER, A.B., TEN BRUMMELHUIS, L.L., PRINS, J.T. \& VAN DER HEIJDEN, F.M.M.A. 2011. Applying the job demands-resources model to work-home interface: a study among medical residents and their partners. Journal of Vocational Behavior, 79:170-180.

BARTOLOME, F. \& EVENS, P.A.L. 1979. Professional lives versus private lives: shifting patterns of managerial commitment. Organizational Dynamics, 7:3-29.

BAUMANN, C. 2011. Work-life interference, psychological conditions, and work engagement at a uranium mine in Namibia. Unpublished master's thesis. University of Namibia, Windhoek.

BRATTON, J. \& GOLD, J. 2003. Human resource management: theory and practice (3rd ed.) Basingstoke: Palgrave Macmillan Publishers.

CAMERON, S., DUTTON, J. \& QUINN, R. 2003. Positive organizational scholarship: foundations of a new discipline. San Francisco, CA: Berrett-Koehler Publishers.

CRAWFORD, E.R., RICH, B.L., BUCKMAN, B. \& BERGERON, J. 2014. The antecedents and drivers of employee engagement. In C. Truss, R. Delbridge, E. Soane, K. Alfes, \& A. Shantz (eds.) Employee engagement in theory and practice (pp. 57-81). Abingdon: Routledge.

CROUTER, A.C. 1984. Spillover from family to work: the neglected side of the work-family interface. Human Relations, 37:425-442.

DELLE FAVE, A., BRDAR, I., FREIRE, T., VELLA-BRODRICK, D. \& WISSING, M.P. 2011. The eudaimonic and hedonic components of happiness: qualitative and quantitative findings. Social Indicators Research, 100:185-207.

DEMEROUTI, E. \& GEURTS, S. 2004. Towards a typology of work-home interaction. Community, Work and Family, 7(3):285-309.

DIEDERICKS, E. \& ROTHMANN, S. 2013. Flourishing of information technology professionals: the role of work engagement and job satisfaction. Journal of Psychology in Africa, 23(2):225-234.

ECKENRODE, J. \& GORE, S. 1990. Stress and coping at the boundary of work and family. In J. Eckenrode $\&$ S. Gore (eds.) Stress between work and family (pp. 1-16). New York: Plenum Press.

EDWARDS, J.R., \& ROTHBARD, N.P. 2000. Mechanisms linking work and family: clarifying the relationship between work and family. Academy of Management Review, 25:178-199.

FAIRLIE, P. 2011. Meaningful work, employee engagement and other key employee outcomes: implications for human resource development. Advances in Developing Human Resources, 13:508-525.

GATTIKER, U.E. \& LARWOOD, L. 1990. Predictors for career achievement in the corporate hierarchy. Human Relations, 43:703-726.

GEURTS, S.A.E. \& DEMEROUTI, E. 2003. Work/non-work interface: a review of theories and findings. In M. Schabracq, J. Winnubst \& C.L. Cooper (eds.) Handbook of work and health psychology (pp. 279-312). Chichester: Wiley.

GEURTS, S.A.E., TARIS, T.W., KOMPIER, M.A.J., DIKKERS, J.S.E., VAN HOOF, M.L.M. \& KINNUNEN, U.M. 2005. Work-home interaction from a work psychological perspective. Work \& Stress, 19:319-339.

GREENHAUS, J.H. \& BEUTELL, N.J. 1985. Sources of conflict between work and family roles. Academy of Management Review, 10:76-88.

GRZYWACZ, J.G. \& MARKS, N.F. 2000. Reconceptualizing the work-family interface: an ecological perspective on the correlates of positive and negative spillover between work and family. Journal of Occupational Health Psychology, 5(1):111-126.

HALBESLEBEN, J.R.B., HARVEY, J. \& BOLINO, M.C. 2009. Too engaged? A conservation of resources view of the relationship between work engagement and interference with family. Journal of Applied Psychology, 94:1452-1465.

HALL, D.T. \& RICHTER, J. 1989. Balancing work life and home life: what can organizations do to help? Academy of Management Executive, 2:212-223.

HARTER, J.K., SCHMIDT, F.L. \& HAYES, T.L. 2002. Business-unit-level relationship between employee satisfaction, employee engagement, and business outcomes: a meta-analysis. Journal of Applied Psychology, 87:268-279. 
HARTER, J.K., SCHMIDT, F.L., KILLHAM, E.A. \& ASPLUND, J.W. 2006. Q12 Meta-analysis. Omaha, NE: Gallup Organization.

HAYES, A.F. 2009. Beyond Baron and Kenny: statistical mediation analysis in the new millennium. Communication Monographs, 76:408-420.

HOLBECHE, L. \& SPRINGETT, N. 2004. In search of meaning in the workplace. West-Sussex: Roffey Park Institute.

HUYSAMEN, G.K. 2004. Methodology for the social and behavioural sciences. Pretoria: Southern Book Publishers.

KAHN, W. 1990. Psychological conditions of personal engagement and disengagement at work. Academy of Management Journal, 33:692-724.

KAHN, W. \& HEAPY, E.D. 2014. Relational contexts of personal engagement at work. In C. Truss, R. Delbridge, E. Soane, K. Alfes, \& A. Shantz (eds.) Employee engagement in theory and practice (pp. 163179). Abingdon: Routledge.

KEYES, C.L.M. 2007. Promoting and protecting mental health as flourishing: a complementary strategy for improving national mental health. American Psychologist, 62:95-108.

KLINE, R.B. 2010. Principles and practice of structural equation modeling. New York: Guilford Press. LEWIS, S. 2011. Positive psychology at work: how positive leadership and appreciative inquiry create inspiring organizations. Chichester: Wiley-Blackwell.

LINGARD, H., BROWN, K., BRADLEY, L., BAILEY, C. \& TOWNSEND, K. 2007. Improving employees' work-life balance in the construction industry: a project alliance case study? Journal of Construction Engineering and Management, 133:807-815.

MARAIS, C., MOSTERT, K., GEURTS, S. \& TARIS, T. 2009. The psychometric properties of a translated version of the Survey Work-Home Interaction - Nijmegen (SWING) instrument. South African Journal of Psychology, 39:202-219.

MARKS, S.R. \& MACDERMID, S.M. 1996. Multiple roles and the self: a theory of role balance. Journal of Marriage and Family, 58:417-432.

MASLACH, C., SCHAUFELI, W.B. \& LEITER, M.P. 2001. Job student burnout. Annual Review of Psychology, 52:397-422.

MATUSKA, K.M. \& CHRISTIANSEN, C.H. 2008. A proposed model of lifestyle balance. Journal of Occupational Science, 15(1):9-19.

MAY, D., GILSON, R. \& HARTER, L. 2004. The psychological conditions of meaningfulness, safety and availability and the engagement of the human spirit at work. Journal of Occupational and Organizational Psychology, 77:11-37.

MOSTERT, K., CRONJÉ, S. \& PIENAAR, J. 2006. Job resources, work engagement and the mediating role of positive work-home interaction of police officers in the North West Province. Acta Criminologica, 19:6487.

MOSTERT, K., PEETERS, M. \& ROST, I. 2011. Work-home interference and the relationship with job characteristics and well-being: a South African study among employees in the construction industry. Stress and Health, 27:e238-e251.

MUNN, S.L. 2013. Unveiling the work-life system: the influence of work-life balance on meaningful work. Advances in Developing Human Resources, 15:401-417.

MUTHÉN, L.K. \& MUTHÉN, B.O. 1998-2012. Mplus user's guide (6th ed.) Los Angeles, CA: Muthén \& Muthén.

OLIVIER, A.L. \& ROTHMANN, S. 2007. Antecedents of work engagement in a multinational oil company. South African Journal of Industrial Psychology, 33(3):49-56.

PARK, Y., FRITZ, C. \& JEX, S.M. 2011. Relationships between work-home segmentation and psychological detachment from work: the role of communication technology use at home. Journal of Occupational Health Psychology, 16(4):457-467.

RAYKOV, T. 2009. Evaluation of scale reliability for unidimensional measures using latent variable modeling. Measurement and Evaluation in Counseling and Development, 42:223-232.

RENN, R.W. \& VANDENBERG, R.J. 1995. The critical psychological states: an under-represented component in job characteristics model research. Journal of Management, 21:279-304. 
ROTHBARD, N.P. 2001. Enriching or depleting? The dynamics of engagement in work and family role. Administrative Science Quarterly, 46:655-684.

ROTHMANN, S. 2013. From happiness to flourishing at work: a southern African perspective. In M.P. Wissing (ed.) Well-being research in South Africa: cross-cultural advances in positive psychology - Volume 4 (pp. 123-152). Dordrecht: Springer.

ROTHMANN. S. 2014. Employee engagement in cultural context. In C. Truss, R. Delbridge, E. Soane, K. Alfes, \& A. Shantz (eds.) Employee engagement in theory and practice (pp. 161-179). Abingdon: Routledge. ROTHMANN, S. \& ROTHMANN, S. (Jr). 2010. Factors associated with employee engagement in South Africa. South African Journal of Industrial Psychology, 36(1):1-12.

ROTHMANN, S. \& WELSH, C. 2013. Employee engagement in Namibia: the role of psychological conditions. Management Dynamics, 22(1):14-25.

RYFF, C.D. 1989. Happiness is everything, or is it? Explorations on the meaning of psychological wellbeing. Journal of Personality and Social Psychology, 57:1069-1081.

SAKS, A.M. 2006. Antecedents and consequences of employee engagement. Journal of Managerial Psychology, 21:600-619.

SCHAUFELI, W.B. \& BAKKER, A.B. 2004. Job demands, job resources, and their relationship with burnout and engagement: a multi-sample study. Journal of Organizational Behavior, 25:1-23.

SIMPSON, M.R. 2008. Engagement at work: a review of the literature. International Journal of Nursing Studies, 1:1-13.

SIRGY, M.J. \& WU, J. 2009. The pleasant life, the engaged life and the meaningful life: what about the balanced life? Journal of Happiness Studies, 10:183-196.

SPREITZER, G.M. 1995. Psychological empowerment in the workplace: dimensions, measurement and validation. Academy of Management Journal, 38:1442-1465.

WANG, J. \& WANG, X. 2012. Structural equation modeling: applications using Mplus. West Sussex: Wiley. 